\title{
CLASSIFICATION AND SELECTION OF TENANTS IN RESIDENTIAL REAL ESTATE: A CONSTRUCTIVIST APPROACH
}

\author{
Manuel B. C. B. F. FONSECA ${ }^{1}$, Fernando A. F. FERREIRA ${ }^{1,2, *}$, \\ Wenchang FANG $^{3}$, Marjan S. JALALI ${ }^{1}$ \\ ${ }^{1}$ ISCTE Business School, BRU-IUL, University Institute of Lisbon, Avenida das Forças Armadas, 1649-026, \\ Lisbon, Portugal \\ ${ }^{2}$ Fogelman College of Business and Economics, University of Memphis, Memphis, TN 38152-3120, USA \\ ${ }^{3}$ Graduate School of Business Administration, National Taipei University, 69, Sec 2, Jian-Kuo N. Rd, \\ Taipei City 10433, Taiwan ROC
}

Received 24 October 2016; accepted 1 June 2017

\begin{abstract}
Choosing a tenant is a key issue in the housing rental market. Knowing, a priori, whether a tenant will pay the rent on time, be able to hold a good relationship with the neighbors or take care of the property (i.e. whether s/he will be a "good" tenant) is not a simple endeavor. It is crucial, however, as it can help save time, money and conflicts that can end up in court. This study aims to address this issue, through the integrated use of cognitive maps and the Decision EXpert (DEX) technique. Grounded on a constructivist logic, the study brought together a panel of experts with experience and knowledge in the residential rental market, in order to identify and articulate the criteria to be taken into account in the classification and selection of tenants. The results achieved show that the integration of these two methodologies (i.e. cognitive maps and DEX) can help increase our understanding of the decision problem at hand, and lead to more informed and potentially better tenant choices. Advantages and limitations of the framework are also discussed.
\end{abstract}

Keywords: decision making, real estate market, classification and selection of tenants, cognitive maps, decision EXpert (DEX).

\section{Introduction}

The recent economic crisis significantly affected Europe, driving down almost all economic activities; and the real estate industry was no exception. This is of relevance, because the real estate market not only has an undeniable importance for economic development, but is also a cornerstone of other economic activities: the real estate market provides shelter to other domestic services (Goodhart \& Hofmann, 2007). Although signs of recovery from the crisis are beginning to emerge, the unique characteristics of the conjuncture it created in the real estate market cannot be overlooked, namely: a lack of liquidity; heterogeneity of assets; and decreasing sales in almost all segments of the real estate industry (Cheng, Lin, \& Liu, 2008; Lin \& Liu, 2008; Cirman, Pahor, \& Verbic, 2015). In the residential rental market, in particular, understanding these unique characteristics is important to ensure minimum rent/price volatility, regardless of the economic conjuncture.
In practical terms, the source of income of a rented house is the tenant. As such, it is a major concern for the landlord to ensure that s/he should choose the best possible option available (i.e. a tenant who pays the rent in full, on time, and takes care of the property). This is not an easy endeavor, however. Knowing, a priori, whether someone will be a "good" tenant is very difficult, due to asymmetric information. Indeed, it is typically only after the tenant actually lives in the property that this asymmetry is reduced, and it is possible to know whether s/he was a "good" choice. Notwithstanding, decision support can be provided for landlords, in terms of tenant selection, before signing the rental contract, as is the aim of the current research. Grounded on a constructivist standpoint, and a process involving face-to-face meetings with an expert panel of landlords and real estate agents, this study aims to provide support for the classification and selection of tenants in the residential rental market.

${ }^{*}$ Corresponding author. E-mails: fernando.alberto.ferreira@iscte.pt or fernando.ferreira@memphis.edu 
Due to the complexity and ill-structured nature of this decision problem, the methodology chosen relies on the combined used of the Strategic Options Development and Analysis (SODA) approach (Ackermann \& Eden, 2001), which is based on cognitive mapping, and the Decision EXpert (DEX) technique (Bohanec \& Rajkovic, 1999). The integrated use of these two operational research (OR) methods should allow the problem at hand (i.e. the classification of tenants in the residential rental market) to be structured and clarified, using the knowledge and expertise of the expert panel members to: (1) define and articulate the criteria to be taken into account in the selection and classification of tenants; (2) group the criteria by clusters and define aggregation rules; and (3) apply and validate the appraisal system created in a real-world context. By allowing for more informed and defensible decisions, we expect that the evaluation system proposed in this study can contribute to reducing conflicts between tenants and landlords in the residential rental market.

The remainder of the paper is organized as follows. The next section presents the literature review, so as to provide the framing of the study. Then, the theoretical background of the techniques applied is provided, followed by the methodological procedures undertaken, the model created and the results obtained, highlighting new insights and practical implications. The final section concludes the paper, highlighting the study's contribution and limitations, and presenting avenues for future research.

\section{Literature review}

Although it is the foundation of almost all the other markets, the real estate market is quite distinct from other economic activities, in particular due to "the fact that its 'product' is not portable" (Case, Goetzmann, \& Rouwenhorst, 2000, p. 2). Yet, as noted by Carter (2011, p. 159), "acquiring shelter is an economic activity in which virtually all members of society participate, either in the rental or owner-occupied markets". This is true not only of individuals, but also organizations, such as firms, hospitals, police departments, government buildings and farms, among many others, that depend on the real estate market to physically exist. The real estate market is not only a basis for other economic activities, but also plays a decisive role in the world economy. As Poterba, Weil, and Shiller (1991, pp. 145-146) note, "house prices are of more than conversational interest to economists. Owner-occupied housing accounts for a greater fraction of household net worth than corporate equity. [...] Movements of real house prices have large effects on household wealth, and potentially on consumer spending. High house prices relative to buildings costs also call forth increased construction activity and channel resources to the building sector". The real estate market can thus impact people's lives, families, companies, as well as banks ( $c f$. Goodhart \& Hofmann, 2007), and may arguably be considered the most important market of all.

In broad terms, the real estate market refers to the trading of real estate (Maier \& Herath, 2009), and can assume three main forms: (1) commercial (e.g. warehouses and retail stores); (2) industrial (e.g. factories, mines and farms); and (3) residential (e.g. undeveloped land, houses and townhomes). Within the last form (i.e. residential), there are two options: sale and rent; and the decisions surrounding them are not always easy. Hjalmarsson, E. and Hjalmarsson, R. (2009, p. 215) note that "the buy versus rent decision is a very large one for most households, and may depend on many factors, not all of which are of a financial nature". The focus in this study will be on the rental market.

Within this submarket, the tenant can plausibly be considered the most important stakeholder, because s/he: (1) serves as the property's source of financial income; (2) interacts with other market players, such as landlords, other tenants and real estate agents; and (3) is the one responsible for taking care of the rented property. It is easy to see, then, why tenant choices matter. No landlord wishes to bear the problems that a "bad" tenant can bring, in particular since the relationship between tenant and landlord is often expected to be long term. In fact, it begins before the contract is even signed, and continues through rents paid, services and upgrades, until the tenant leaves (Larsen \& Sommervoll, 2009; Gbadegesin \& Oletubo, 2013).

This long-term relationship can be seen as a good investment if it is with a "good" tenant - it ensures the property is looked after, good relations are maintained, and substitution costs, such as search and contract renovation costs, are avoided. These transaction costs suggest avoiding turnover is generally in the landlord's best interests. Contractual clauses aside, one of the best ways to accomplish this objective is to choose the "right" tenant ( $c f$. Miceli \& Sirmans, 1999). Indeed, it can be argued to be even more important than contractual clauses, because these take time to be drawn up, negotiated and agreed upon, and can be costly to enforce if disputes end up in court. Olawande (2011, p. 4) reinforces this view: "tenant selection is the most important aspect of successful property management. [...] Most mistakes can be corrected; however, putting wrong tenant in possession can not only cost lots of money, but also endless frustration. [...] Without proper screening procedures, the agents and owners can find themselves stuck with potentially bad tenants".

It is unsurprising, then, that this topic has attracted researchers' attention. Indeed, there have been several contributions on this topic in the literature, from areas ranging from marketing, consumer behavior and psychology to finance (Anikeeff, 1996; Chye, Chin, \& Peng, 2004; Burnaz \& Topcu, 2011; Ju, Wenbin, \& Bei, 2011; Baklouti, 2014), and using different methodologies. These studies have allowed several determinants able to predict a "good" tenant to be identified, namely: the tenant's annual income, credit access and psychological profile ( $c f$. Olawande, 2011); as well as demographic factors such as: age, gender, social class, marital status, and number of dependents, among others (Jackson, Jones, \& Balsmeir, 1986; Yau \& Davis, 1994; Olawande, 2011; Gbadegesin \& Oletubo, 2013). Table 1 summarizes some of these studies, highlighting their contributions and limitations. 
Table 1. Classification and selection methods: contributions and limitations

\begin{tabular}{|c|c|c|c|}
\hline Authors & Method & Contribution / originality & Limitations acknowledged by the author/s \\
\hline $\begin{array}{l}\text { Jackson et al. } \\
(1986)\end{array}$ & Probit Analysis & $\begin{array}{l}\text { Classification of tenants based on their } \\
\text { probability of being accepted or rejected for } \\
\text { federally subsidized housing. }\end{array}$ & $\begin{array}{l}\text { The specificity of the sample does not allow } \\
\text { for the generalization of results. }\end{array}$ \\
\hline $\begin{array}{l}\text { Yau and Davis } \\
\text { (1994) }\end{array}$ & $\begin{array}{l}\text { Tenant Selection } \\
\text { Decision Support } \\
\text { System (TSDSS) }\end{array}$ & $\begin{array}{l}\text { Uses multiple criteria analysis for the } \\
\text { classification and selection of tenants for a } \\
\text { shopping mall. }\end{array}$ & $\begin{array}{l}\text { Model created for shopping mall tenants, } \\
\text { requiring adaptations to be used by different } \\
\text { decision makers and in different real estate } \\
\text { contexts. }\end{array}$ \\
\hline $\begin{array}{l}\text { Aickelin and } \\
\text { Dowsland } \\
\text { (2002) }\end{array}$ & $\begin{array}{l}\text { Enhanced Direct } \\
\text { and Indirect } \\
\text { Algorithm }\end{array}$ & $\begin{array}{l}\text { Uses a model for classification of commercial } \\
\text { tenants to solve a mall layout and tenant } \\
\text { selection problem. }\end{array}$ & $\begin{array}{l}\text { Difficulty in defining the weights of the } \\
\text { selected variables. }\end{array}$ \\
\hline Furick (2006) & Neural Networks & $\begin{array}{l}\text { Application of reports and credit scores to the } \\
\text { residential real estate market in order to create a } \\
\text { model that can forecast future tenant behavior. }\end{array}$ & $\begin{array}{l}\text { The sample is not random and is centered } \\
\text { on a specific apartment complex located in } \\
\text { a specific city. }\end{array}$ \\
\hline $\begin{array}{l}\mathrm{Zu}, \mathrm{Wu} \text { and } \\
\text { Wang }(2010)\end{array}$ & $\begin{array}{l}\text { Extended Bayes } \\
\text { Model }\end{array}$ & $\begin{array}{l}\text { The weights of the attributes are changed in the } \\
\text { Bayes model depending on their effect on the } \\
\text { classification. }\end{array}$ & $\begin{array}{l}\text { The model is used for clients (and not for } \\
\text { tenants). }\end{array}$ \\
\hline $\begin{array}{l}\text { Olawande } \\
(2011)\end{array}$ & $\begin{array}{l}\text { Analytic } \\
\text { Hierarchic } \\
\text { Process (AHP) }\end{array}$ & Uses AHP to select tenants. & $\begin{array}{l}\text { The study is conducted in Nigeria, with } \\
\text { criteria defined by a panel of Nigerian } \\
\text { experts. As such, some of the criteria are } \\
\text { related to cultural aspects, and the results } \\
\text { cannot be extrapolated. }\end{array}$ \\
\hline $\begin{array}{l}\text { Gbadegesin } \\
\text { and Oletubo } \\
(2013)\end{array}$ & $\begin{array}{l}\text { Hierarchical } \\
\text { Cluster Analysis } \\
\text { (HCA) }\end{array}$ & $\begin{array}{l}\text { Uses HCA to determine which are the most } \\
\text { important criteria in tenant selection and } \\
\text { highlights the fact that one should take into } \\
\text { account several criteria when selecting tenants. }\end{array}$ & $\begin{array}{l}\text { The study is conducted in just one city, } \\
\text { Ibdaban. }\end{array}$ \\
\hline
\end{tabular}

The contributions presented in Table 1 are representative of the importance of the research topic at hand; but, as the table also shows, are not without their limitations. In particular, statistical data is required in most cases for a good selection and classification of tenants; and there are practical difficulties in defining evaluation criteria and the trade-offs among them. Thus, there appears to be room for further research into the field.

Taking into account the baseline convictions of the multiple criteria decision analysis (MCDA) approach (i.e. the interrelation between objective and subjective criteria in the decision-making framework, learning through participation, and constructivism) (for deeper discussion, see Bana e Costa, Stewart, \& Vansnick, 1997; Belton \& Stewart, 2002), this study resorts to the combination of cognitive mapping and DEX to create a more complete and reliable evaluation system for the classification and selection of tenants, able to overcome some of the limitations of the existing contributions.

\section{Methodology}

\subsection{Background on cognitive mapping}

As already pointed out, this study assumes the baseline convictions of the MCDA approach. According to Bana e Costa et al. (1997) and Belton and Stewart (2002), the decision-making process is usually divided into three stages, namely: (1) the structuring phase, where the objective is to gather and shape the decision makers' value judg- ments and preferences in order to structure the decision problem at hand; (2) the evaluation phase, in which an evaluation model that represents the experts' preferences is built; and (3) the recommendations phase, in which recommendations are provided based on the framework created and the discussion underlying its development. One of the most common methods used during the structuring phase is SODA (Ackermann \& Eden, 2001; Eden \& Ackermann, 2001), which is grounded on cognitive mapping and helps individuals to project and explain the way they see a decision problem (Shaw, Ackermann, \& Eden, 2003; F. Ferreira, Jalali, Bento, Marques, \& J. Ferreira, 2017a).

Lima (2003) refers to human cognitive process as a set of mental activities such as thinking, imagination, memory and problem solving, which occur differently from individual to individual, according the way these individuals perceive and interpret real-world phenomena and respective decision situations. This interpretation of reality can be made explicit by cognitive mapping, which allows cause-and-effect relationships between concepts to be identified and modeled (Eden, 1988; Kwahk \& Kim, 1999; Ferreira, Jalali, Zavadskas, \& Meidute-Kavaliauskienè, 2017b). This technique also allows for in-depth discussion among different decision makers, generating large amounts of data and information on the decision situation at hand (Montibeller, Ackermann, Belton, \& Ensslin, 2008). As a problem-structuring methodology, cognitive mapping has been widely applied in different decision scenarios, and its main advantages result from its ability to help: (1) structure complex decision problems; (2) increase 


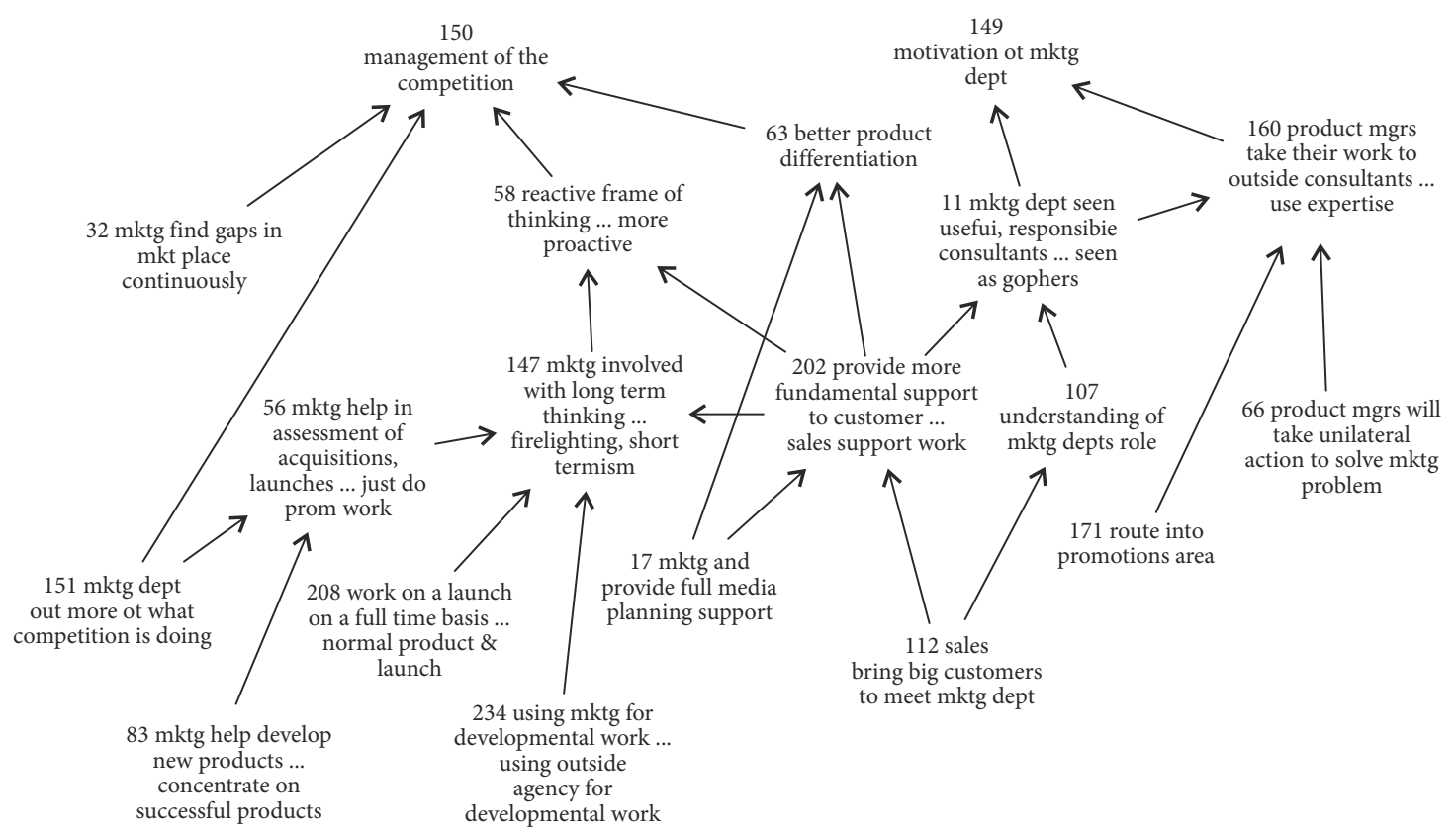

Source: Eden (2004, p. 675)

Figure 1. Example of a cognitive map [partial view]

understanding of decision situations; (3) manage large amounts of data; and (4) contribute to reduce the rate of omitted criteria in the decision-making framework (Belton \& Stewart, 2002; Montibeller et al., 2008). As a result, "both transparency and understanding of the decision problem" are typically increased (F. Ferreira, Marques, Bento, J. Ferreira, \& Jalali, 2015b, p. 2693).

In practical terms, a cognitive map consists of chains of concepts connected by arrows, which represent the cause-and-effect relationships between them (Eden \& Ackermann, 2004). Figure 1 exemplifies part of a cognitive map.

As shown in Figure 1, the arrows can present positive $(+)$ or negative (-) signs, depending on the type of relationship between concepts: "a positive relationship occurs when a change in a predecessor concept causes a similar change in the successor: an increase (decrease) in the first causes an increase (decrease) in second. With a negative relationship, an increase (decrease) in the predecessor causes a decrease (increase) in second" (Klein \& Cooper, 1982, p. 64).

Although subjective in nature, such maps can be of great use in organizing and structuring complex decision problems, enabling different perspectives to be considered and harmonized based on discussion and exchange of experiences among decision makers (for developments, see Belton \& Stewart, 2002; Eden, 2004; Eden \& Ackermann, 2004; Montibeller et al., 2008 and F. Ferreira, Spahr, Sunderman, Banaitis, \& J. Ferreira, 2017c).

\subsection{The DEX approach}

The second phase of the MCDA approach is the evaluation phase. In this phase, after understanding and structuring the decision problem, the experts' value preferences are gathered to construct an evaluation model (Belton \& Stewart, 2002). In this study, the model was built following the procedures of the DEX technique (Bohanec \& Rajkovic, 1999), which uses qualitative attributes with discrete scales that consist of words instead of numbers to sort choice alternatives. The technique thus allows for the combination of MCDA, expert systems, machine learning and fuzzy logics, holding great potential when dealing with uncertain or missing data (Bohanec \& Rajkovic, 1999). Taskova, Stojanova, Bohanec, and Dzerpski (2007, p. 480) note that the DEX technique is "particularly suitable for a hierarchical decomposition of evaluation problems that require judgment and qualitative reasoning".

Technically, DEX uses decision rules to obtain value functions (Bohanec, 2014), which are responsible for aggregating combinations of lower-level attributes (i.e. $X_{i}$ ) into an upper-level criterion $Y$, as shown in formulation (1):

$$
f . \mathrm{X}_{1 \times} \mathrm{X}_{2 \times \ldots \times} \mathrm{X}_{n} \rightarrow \mathrm{Y} \text {. }
$$

In practice, this utility function maps all the combinations of lower-level attributes into an aggregate evaluation criterion $Y$. The mapping is presented in a table where each row (i.e. decision rule), provides the value of $f$ for one combination of lower-level attribute values. This is commonly defined as an if-then rule, according to formulation (2) (cf. Bohanec, 2014):

$$
\begin{aligned}
& \text { if } X_{1}=\text { value }_{1} \text { and } X_{2}=\text { value }_{2} \text { and } \ldots \text { and } X_{n}=\text { value }_{n}, \\
& \text { then } Y=\text { value (orvalue interval). }
\end{aligned}
$$

Overall, the DEX models are comprised by: (1) attributes (i.e. variables that represent the basic characteristics of the choice alternatives); (2) scales, which should be 
qualitative and ordered preferentially, either in decreasing or increasing order; (3) a hierarchy of attributes, which represents the decomposition of the decision problem and the relationships between attributes; and (4) decision rules, used to evaluate attributes (Bohanec, Rajkovic, Zupan, \& Bratko, 2013). The simplicity of DEX, its use of qualitative modeling, the fact that its application involves active support from a facilitator, make the technique ideal to tackle essentially qualitative, ill-structured, real-life decision problems (Bohanec \& Rakjovic, 1999; Bohanec et al., 2013), as is the case of the classification and selection of tenants in the residential rental market. In operational terms, DEX is supported by an interactive software package called DEXi, which, according to Bohanec et al. (2013, p. 2), is "extremely useful even for most difficult decisionmaking tasks".

\section{Application and results}

As noted above, the aim of this study is to develop a framework to assist decision making in what pertains to residential tenant selection. The goal is thus to develop a multiple criteria evaluation model for this purpose; and in doing so, assessing the applicability of the combined use of the SODA and DEX methodologies for this purpose.

Following the premise that decision-making groups "should have between 6 and 10 key individuals" (Eden \& Ackermann, 2004, p. 618), the expert panel in this study was composed of six participants with ages ranging between 29 and 70 years old. The participants all had expertise in the residential rental market: four were landlords with practical experience in short- and long-term rental contracts, and two were professional real estate agents, operating in the city of Lisbon, Portugal. It is worth noting that, due to the constructivist and process-oriented nature of our framework, when correctly adjusted, the procedures followed can work well with any other expert panel (cf. Belton \& Stewart, 2002; Ferreira et al., 2017c). Two group meetings, with an average duration of four hours each were carried out, guided by two experienced facilitators, who coordinated the negotiation process between the panel members. The first session pertained to the structuring phase, as described below.

\subsection{Developing the cognitive map}

The first stage of the MCDA approach - the structuring phase - is intended to clarify the problem, and allow participants' points of views to be considered and analyzed for model building. Following the guidelines set out by Ackermann and Eden (2001), Eden and Ackermann (2001), Ferreira (2016) and Jalali, F. Ferreira, J. Ferreira, and Meidutè-Kavaliauskienè (2016), and in order to avoid misunderstandings, the first group session started with a presentation of the research objectives and methodological procedures to be applied. Participants were then presented with the following trigger question: "Based on your values and personal experience, how do you identify an excellent tenant?", which served as the starting point for discussion and allowed the "post-its technique" to be applied (Ackermann \& Eden, 2001; Eden \& Ackermann, 2001). This technique operationalizes the SODA approach through the use of post-its, on which each decision maker writes the criteria that $\mathrm{s} / \mathrm{he}$ considers pertinent in responding to the decision problem presented, with the rule that there should only be one criterion per post-it. A fundamental aspect of this process is the underlying discussion among the panel members, such that each criterion put forth, its meaning and implications are thoroughly debated.

Once the panel feels they have achieved "saturation" in the identification of criteria, they are asked to group them into clusters. In the current study, three main clusters were identified: Guarantees and Financial Indicators; Owner's Initial Analysis/Feeling; and Tenant Profile, with Tenant Profile then divided into three sub-clusters: Behavioral Aspects; Physical Aspects; and Family Issues. In the final part of this first meeting, the decision makers were invited to perform a mean-end analysis and regroup the post-its (i.e. criteria) within each cluster, according to their relative importance. Figure 2 presents two snapshots of different stages of this structuring process, which are important to demonstrate the dynamics behind the application of the post-its technique.

Using the Decision Explorer software (www.baxia. com), a group cognitive map was then created based on the application of the post-its technique. Figure 3 illustrates the final version of this map, which was presented, analyzed, discussed and validated by the decision makers.

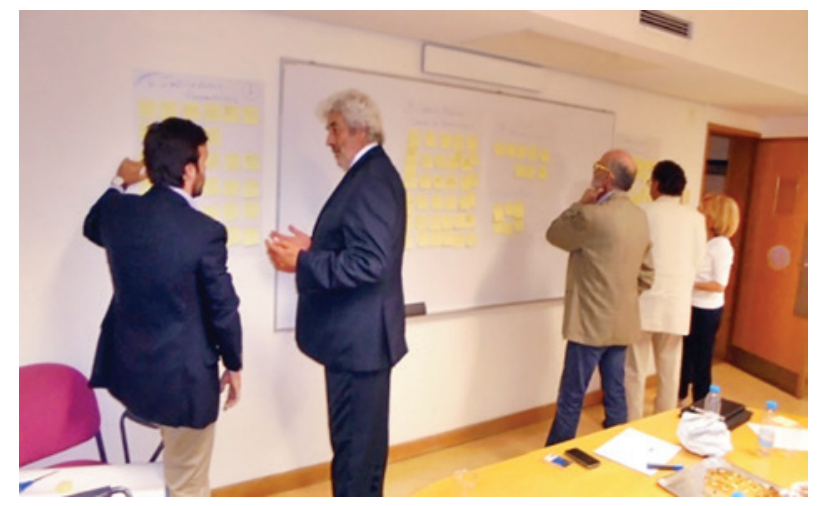

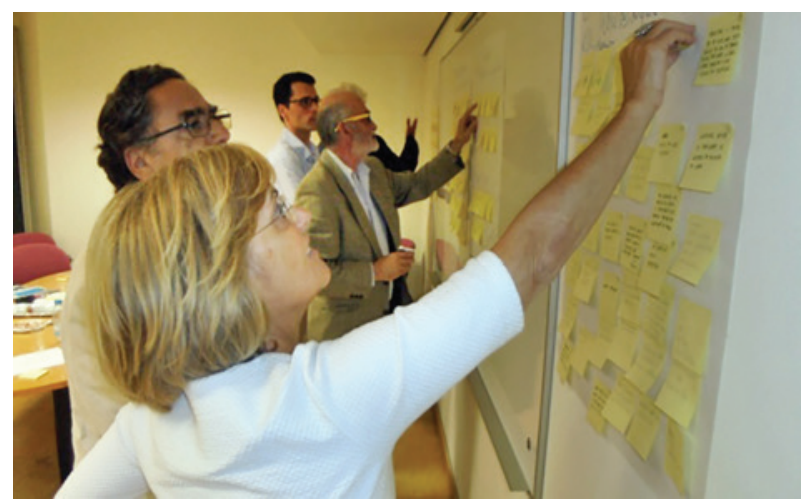

Figure 2. Snapshots of the application of the "post-its technique" 


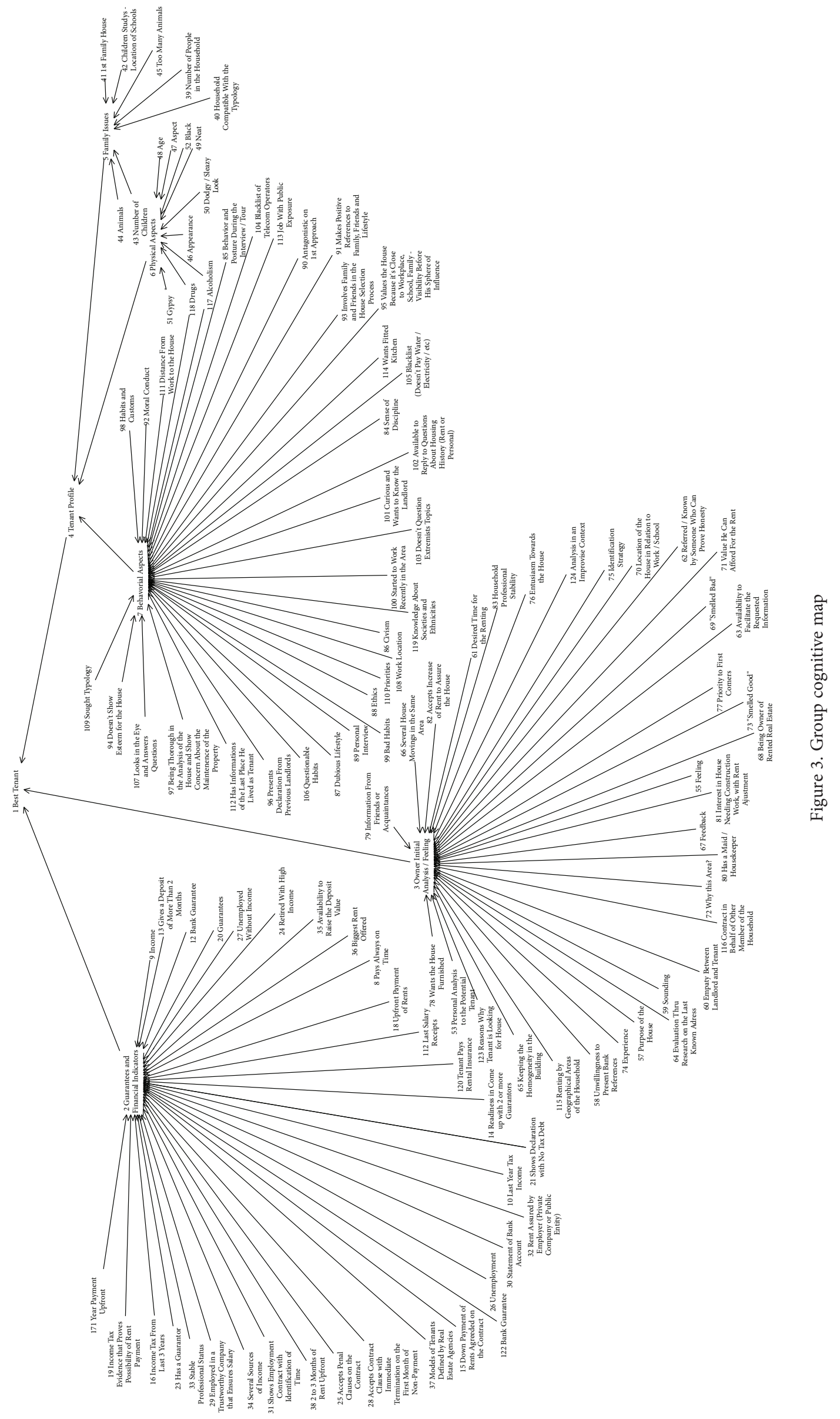




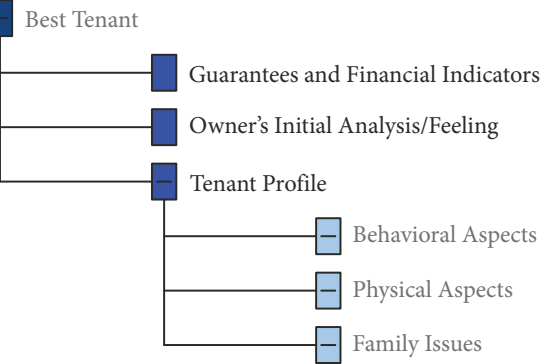

Figure 4. Value tree

Following the methodological guidelines provided by Keeney $(1992,1996)$, a value tree was constructed based on the collective cognitive map, as shown in Figure 4. Although not always a smooth transition (for discussion, see Ferreira, Santos, Rodrigues, \& Spahr, 2014; Ferreira, Jalali, Meidutè-Kavaliauskienè, \& Viana, 2015a; Filipe, Ferreira, \& Santos, 2015; Gonçalves, Ferreira, Jalali, \& MeidutèKavaliauskiene, 2016; Jalali et al., 2016), this step of the process proved very valuable and was considered of extreme importance by the participants involved.

The first criterion in Figure 4, CTR1 - Guarantees and Financial Indicators - refers to the financial guarantees the tenant is able to present before signing the rental contract, such as tax returns for the previous three years, pay slips, stable professional situation or other evidence indicating ability to pay the rent. CTR2 - Owner's Initial Analysis/Feeling encompasses issues such as reasons why the tenant is looking for a house, last known address and the landlord's initial feeling or intuition, among others. CTR3 - Tenant Profile pertains to the perceived characteristics and stability of the tenant and respective household, and incorporates three sub-clusters, namely: Behavioral Aspects (CTR4), which comprises a set of behavioral characteristics, such as habits and mores, lifestyle, ethics and civism; Physical Aspects (CTR5), which relate to factors such as age and appearance; and Family Issues (CTR6), which includes elements such as children, pets and number of people in the household.

As noted above, the transition from the collective cognitive map to the value tree was challenging, due to the different perspectives held by the panel members. However, this allowed for a both lengthier and more in depth discussion of the criteria identified and the relationships between them. Having arrived at the tree of criteria, it became apparent that it allows for a more direct observation of the information contained in the map, thus facilitating the definition of evaluation scales and decision rules for each cluster and sub-cluster identified.

\subsection{Defining evaluation scales and decision rules}

According to the theoretical guidelines of the DEX approach, the evaluation scales should be qualitative, discrete and ordered. In this study, after group discussion and negotiation, the scales were defined based on four performance levels: (1) Bad/Unacceptable; (2) Acceptable; (3) Good; and (4) Excellent. Figure 5 presents the semantic evaluation scales defined for each attribute.

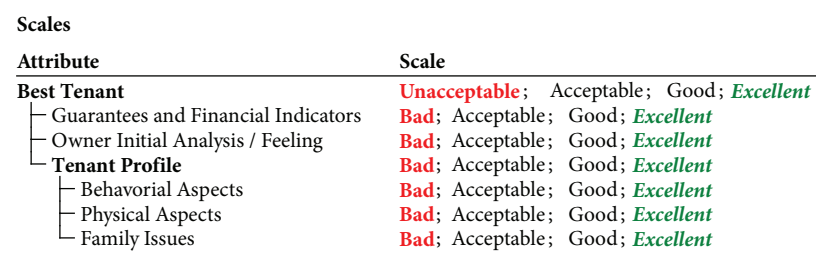

Figure 5. Evaluation scales

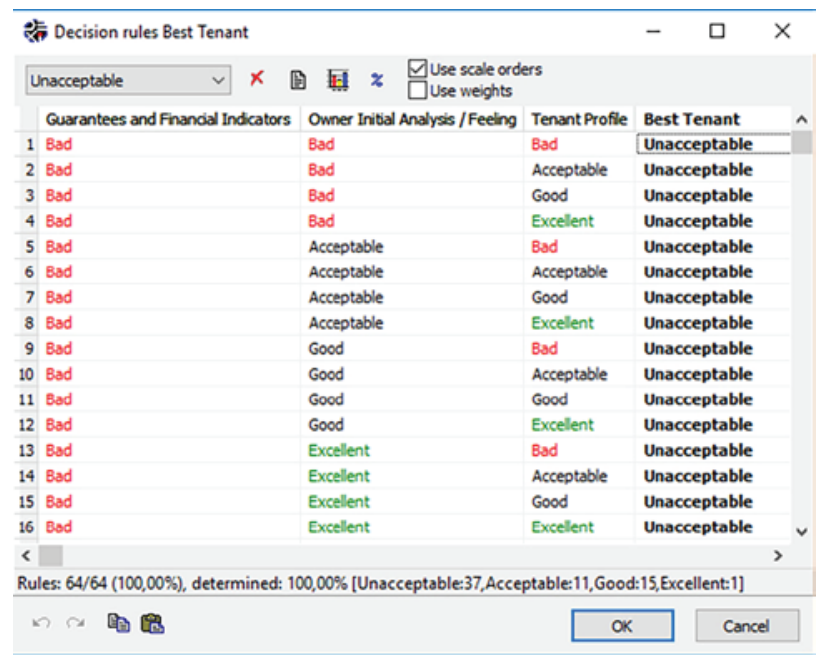

Figure 6. Utility function for Tenant Profile

The next step was then to define the decision rules and consequent utility functions. This took place in a second group meeting and was grounded on the cognitive map and value tree previously validated by the panel members. Figure 6 exemplifies this, illustrating the decision rules defined for the Tenant Profile cluster.

In total, 64 decision rules were defined for each of the aggregated attributes (i.e. Tenant Profile and Best Tenant). Following Figure 6, the attributes Guarantees and Financial Indicators, Owner's Initial Analysis/Feeling and Tenant Profile have four values each, and the number of rows (i.e. elementary decision rules) is $4^{\wedge} 3=64$. This means that each row provides a value of Best Tenant for one combination of Guarantees and Financial Indicators, Owner's Initial Analysis/Feeling and Tenant Profile. The fourth row, for instance, means the following (cf. formulation (2)):

If Guarantees and Financial Indicators $=$ Bad,

Owner's Initial Analysis/Feeling=Bad and Tenant

Profile=Excellent, then Best Tenant=Unacceptable.

\subsection{Classifying tenants: framework application and validation}

Belton and Stewart (2002, p. 24) state that the evaluation phase involves "a search for consensus between possibly highly divergent, and often highly emotive and intangible, interests, taking into consideration many uncertainties and judgmental imprecision". To obtain this consensus, the next stage consisted of testing the practical relevance of the framework. An apartment with specific characteristics was publicly announced for rental purposes, and seven actual potential 

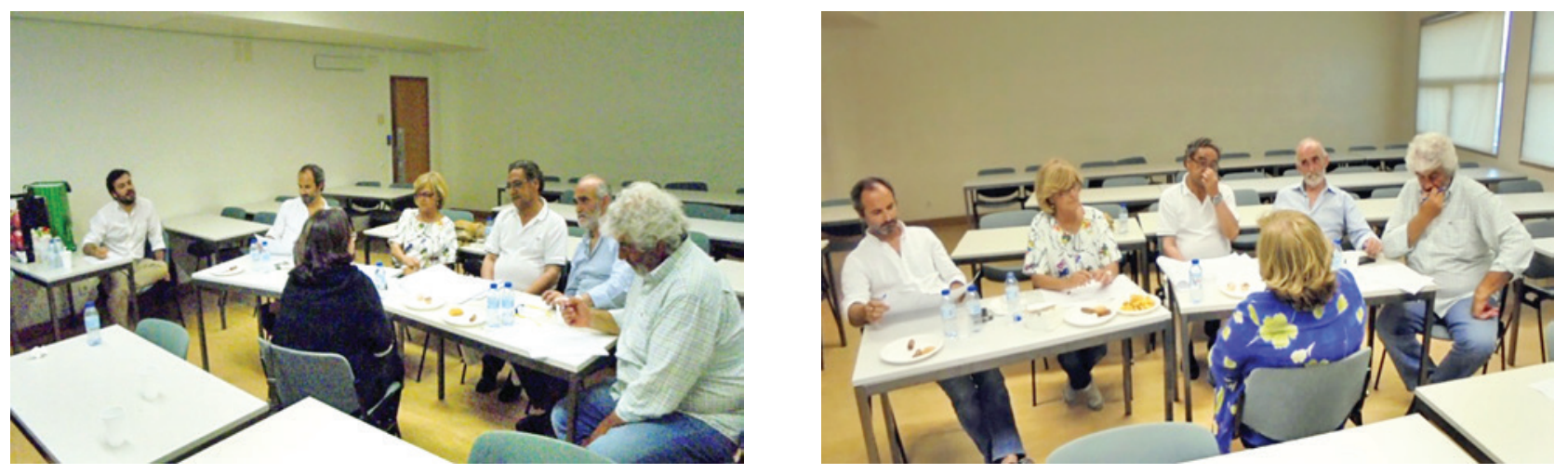

Figure 7. Snapshots of the Alphas' interviews

\begin{tabular}{|c|c|c|c|c|c|}
\hline Attribute & Alpha 1 & Alpha 2 & Alpha 3 & Alpha 4 & Alpha 5 \\
\hline $\begin{array}{l}\text { Best Tenant } \\
\begin{array}{|l}\text { - Guarantees and Financial Indicators } \\
\text { - Owner Initial Analysis / Feeling } \\
\text { Tenant Profile } \\
\text { - Behavorial Aspects } \\
\text { - Physical Aspects } \\
\text { Family Issues }\end{array}\end{array}$ & $\begin{array}{l}\text { Good } \\
\text { Good } \\
\text { Good } \\
\text { Acceptable } \\
\text { Acceptable } \\
\text { Good } \\
\text { Good }\end{array}$ & $\begin{array}{l}\text { Good } \\
\text { Good } \\
\text { Good } \\
\text { Acceptable } \\
\text { Acceptable } \\
\text { Good } \\
\text { Good }\end{array}$ & $\begin{array}{l}\text { Good } \\
\text { Good } \\
\text { Good } \\
\text { Acceptable } \\
\text { Acceptable } \\
\text { Good } \\
\text { Acceptable }\end{array}$ & $\begin{array}{l}\text { Unacceptable } \\
\text { Bad } \\
\text { Bad } \\
\text { Bad } \\
\text { Acceptable } \\
\text { Acceptable } \\
\text { Bad }\end{array}$ & $\begin{array}{l}\text { Unacceptable } \\
\text { Acceptable } \\
\text { Bad } \\
\text { Acceptable } \\
\text { Acceptable } \\
\text { Acceptable } \\
\text { Good }\end{array}$ \\
\hline Attribute & Alpha 6 & Alpha 7 & & & \\
\hline $\begin{array}{l}\text { Best Tenant } \\
\begin{array}{l}\text { - Guarantees and Financial Indicators } \\
\text { - Owner Initial Analysis / Feeling } \\
\text { Tenant Profile } \\
\text { - Behavorial Aspects } \\
\text { - Physical Aspects } \\
\text { Family Issues }\end{array}\end{array}$ & $\begin{array}{l}\text { Acceptable } \\
\text { Acceptable } \\
\text { Good } \\
\text { Good } \\
\text { Good } \\
\text { Good } \\
\text { Good }\end{array}$ & $\begin{array}{l}\text { Acceptable } \\
\text { Acceptable } \\
\text { Good } \\
\text { Good } \\
\text { Good } \\
\text { Good } \\
\text { Acceptable }\end{array}$ & & & \\
\hline
\end{tabular}

Figure 8. Evaluations of the Alphas [overall and per attribute]

tenants were interviewed by the group. It is worth highlighting that the experts did not know these potential tenants beforehand, meaning that the evaluation of each candidate was made spontaneously and according to the criteria defined in the cognitive map and value tree. The candidates (henceforth Alphas) were aged between 23 and 70 years old, had different professional statuses, and distinct incomes and household configurations. Figure 7 presents snapshots of the interviews conducted, which are important to exemplify the interaction established between the group members and the Alphas, projecting the dynamics of the processes followed.
Following the interviews, a rating was obtained for each Alpha. Figure 8 presents the results obtained.

According to the panel members, the first three Alphas had a final score of Good; Alpha 4 and Alpha 5 were scored Unacceptable, meaning that they would be immediately rejected; and Alpha 6 and Alpha 7 were considered Acceptable. Figure 9 presents the Alphas' overall evaluation.

After a careful analysis of the results, two major aspects emerged from the group discussion. First, although Alpha 1, Alpha 2 and Alpha 3 were classified as Good tenants, Alpha 1 was considered, based on the criteria

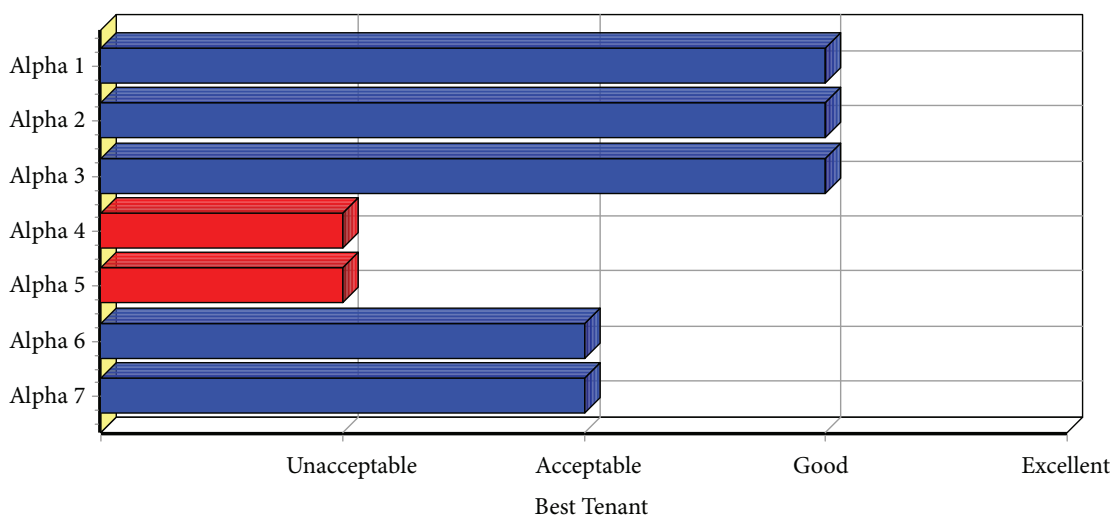

Figure 9. Overall evaluation of the Alphas 
presented in the value tree and cognitive map, the best tenant overall. Second, on the Owner's Initial Analysis/ Feeling criteria, Alpha 5 was scored as "Excellent" and "Good" by two panel members, but as "Bad" by the remaining four. After discussion, it was possible to observe that the better scores were given by the youngest panel members, and as such might be related with their lack of experience when compared to the other four decision makers. Still, this phenomenon was important to support the conclusion that the framework developed in this study can be used by people with different opinions and beliefs, reinforcing its potential in practical terms.

Although the results obtained are encouraging, they are also idiosyncratic, meaning that generalizations and extrapolations to other contexts without the necessary adjustments are not recommended. Still, a battery of "plusminus-1" and dominance analyses were carried out to validate the results and check the stability of the evaluation system created. As an example, Figure 10 presents the "plus-minus-1" analysis carried out for Alpha 1 (a file containing all these analyses can be provided upon request).

According to the "plus-minus-1" analyses carried out for all the Alphas, one can assume that the evaluation system created in this study is little sensitive to +1 changes, which demonstrates that the decision makers, as a group, were quite cautious in the evaluations carried out. In fact, due to the decision rules defined by the group, the system is more sensitive when the Alphas' local profiles are considered Poor or Acceptable.

Because our framework should be seen as a learning tool able to provide well-focused improvement sugges-

\begin{tabular}{lll} 
Attribute & $\mathbf{- 1}$ & Alpha $\mathbf{1}$ \\
\hline Best Tenant & & Good \\
- Guarantees and Financial Indicators & Acceptable & Good \\
- Owner Initial Analysis / Feeling & Acceptable & Good \\
- Behavorial Aspects & Unacceptable & Acceptable \\
- Physical Aspects & & Good \\
- Family Issues & & Good
\end{tabular}

Figure 10. "Plus-minus-1" analysis for Alpha 1

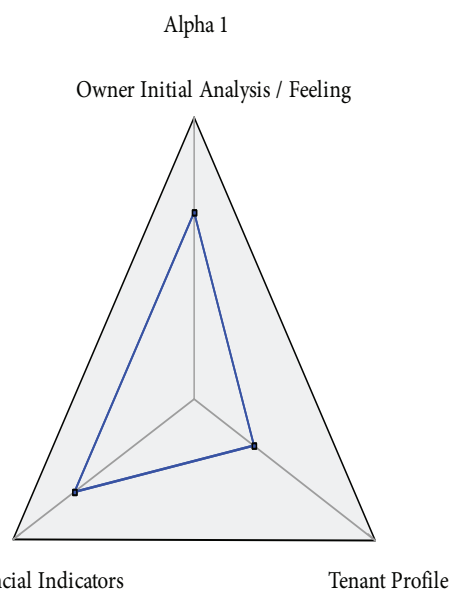

tions, radar charts were additionally created to analyze each Alpha's strengths and weaknesses. Figure 11 exemplifies this exercise, revealing the performance profiles of Alpha 1 and Alpha 6.

As can be seen, these radar charts highlight the need for improvement in the Tenant Profile of Alpha 1, as well as in the Guarantees and Financial Indicators of Alpha 6. By focusing our attention on Alpha 1, we have two attributes with identical local performance level (i.e. Good), namely Guarantees and Financial Indicators, and Owner's Initial Analysis/Feeling. However, Alpha 1 scores only Acceptable on the Tenant Profile dimension. In fact, none of the Alphas presented a classification of Excellent. Theoretically, this means that there is room for improvement in all attributes. However, in this case, priority should be given to the attribute that is at the lowest level.

By displaying evaluation results according to two selected dimensions, a scatter chart provides the basis for dominance analyses. Figure 12 exemplifies this exercise, where the dimensions selected were Tenant Profile and Guarantees and Financial Indicators.

As can be seen, when compared to Alpha 5 and Alpha 4, Alpha 3 and Alpha 7 are better options for the landlord. It should also be noted that, although they do not appear in the image, Alpha 6 occupies the same position as Alpha 7, and Alpha 1 and Alpha 2 are in the same position as Alpha 3, and so also constitute better options than Alpha 4

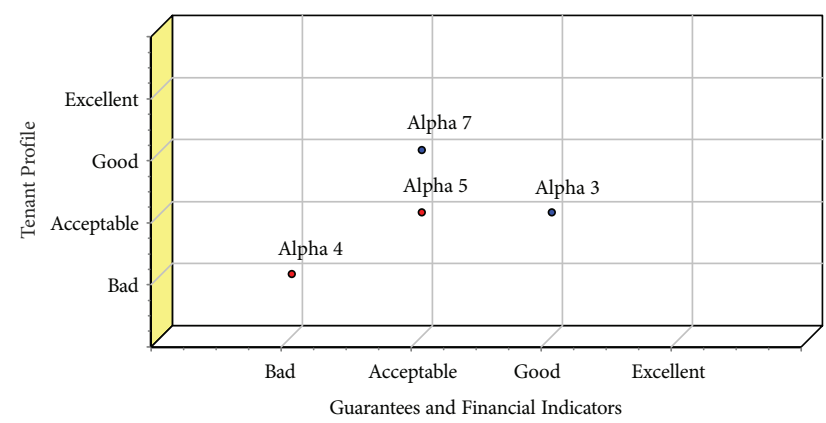

Figure 12. Scatter/dominance chart

Alpha 6

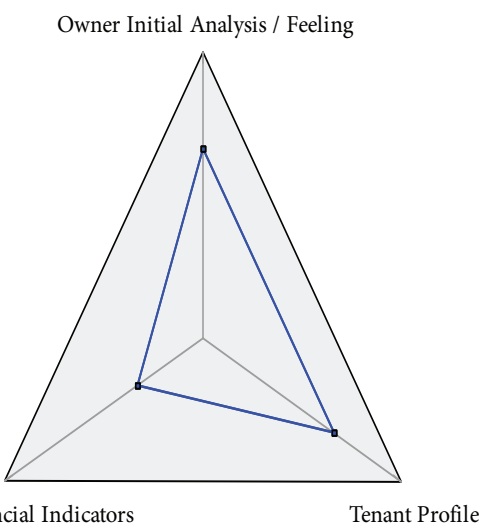

Figure 11. Examples of radar charts 
and Alpha 5. These analyses were particularly important to promote additional discussion among the participants, allowing for the practical validation of the framework (for technical details on this type of analyses, see Bohanec et al., 2013; Ferreira et al., 2017c).

\section{Conclusion and recommendations}

This study acknowledges the importance of a correct classification and selection of tenants, and the evaluation system created can serve as a decision support for the decision making of landlords and real estate agents in this regard. We have found no previous evidence of the combined use of cognitive mapping and DEX to address this decision problem.

The procedures followed and the classification results achieved were validated both by the expert panel members involved in this study and by the "plus-minus-1" and dominance analyses performed, allowing for greater transparency in the classification and selection of tenants in the residential rental market. In fact, transparency and simplicity in decision making are characteristics that became evident for the members of the expert panel in this study. Our proposal was furthermore reinforced by the direct involvement of the decision makers, who provided consistency, functionality and realism to the system developed. It is worth noting that despite its subjective nature, the framework developed is flexible enough to accommodate new information and be periodically updated. Indeed, as already pointed out in the literature, "there is less emphasis on outputs per se and more focus on process" (Bell \& Morse, 2013, p. 962).

Given the results obtained, it seems evident that the integrated use of cognitive mapping and DEX holds great potential, in methodological terms, for broadening our understanding of the factors behind the classification and selection of tenants in the residential rental market. Notwithstanding, the framework's limitations with regard to the great amount of subjectivity still inherent in the evaluation process, as well as its idiosyncratic nature, should be borne in mind. In this sense, it is recommended that future research initiatives consider involving: (1) other decision makers with intrinsic characteristics different from those of the present study; and (2) other MCDA techniques to compare the results (for examples of these techniques, see Zavadskas \& Turskis, 2011). Any improvement or update will be a welcome addition to this evolving research topic.

\section{Acknowledgements}

A previous and non-copyrighted version of this paper was presented at the 2017 BAI International Conference, held in Hiroshima, Japan. Records of the group meetings, including pictures and software outputs, and non-confidential information of the study can be obtained from the corresponding author upon request. The authors gratefully acknowledge the contribution and willingness of the expert panel members: Ana Lourenço, Miguel Correia, Fernando Santos, Pedro Brito Lima, Miguel Pimenta and José Fonseca.

\section{References}

Ackermann, F., \& Eden, C. (2001). SODA - journey making and mapping in practice. In J. Rosenhead \& J. Mingers (Eds.), $R a$ tional analysis for a problematic world revisited: problem structuring methods for complexity, uncertainty and conflict (pp. 43-60). (2nd ed.). Chichester: John Wiley \& Sons.

Aickelin, U., \& Dowsland, K. (2002). Enhanced direct and indirect genetic algorithm approaches for a mall layout and tenant selection problem. Journal of Heuristics, 8(5), 503-514. https://doi.org/10.1023/A:1016536623961

Anikeeff, M. (1996). Shopping center tenant selection and mix: a review. In J. Benjamin (Ed.), Research issues in real estate: megatrends in retail real estate (pp. 215-238). Dordrecht: Kluwer Academic Publishers. https://doi.org/10.1007/978-94-009-1802-3_11

Baklouti, I. (2014). A psychological approach to microfinance credit scoring via a classification and regression tree. Intelligent Systems in Accounting, Finance and Management, 21(4), 193-208. https://doi.org/10.1002/isaf.1355

Bana e Costa, C., Stewart, T., \& Vansnick, J. (1997). Multicriteria decision analysis: some thoughts based on the tutorial and discussions sessions of the ESIGMA meetings. European Journal of Operational Research, 99(1), 28-37. https://doi.org/10.1016/S0377-2217(96)00380-3

Bell, S., \& Morse, S. 2013. Groups and facilitators within problem structuring processes. Journal of the Operational Research Society, 64(7), 959-972. https://doi.org/10.1057/jors.2012.110

Belton, V., \& Stewart, T. (2002). Multiple criteria decision analysis: an integrated approach. Dordrecht: Kluwer Academic Publishers. https://doi.org/10.1007/978-1-4615-1495-4

Bohanec, M. (2014). DEXi: program for multi-attribute decision making user's manual. Ljubljana University, Slovenia.

Bohanec, M., \& Rajkovic, V. (1999). Multi-attribute decision modeling: Industrial applications of DEX. Informatica, 23(4), 487-491.

Bohanec, M., Rajkovic, V., Zupan, B., \& Bratko, I. (2013). DEX methodology: three decades of qualitative multi-attribute modeling. Informatica, 37(1), 49-54.

Burnaz, S., \& Topcu, I. 2011. A decision support on planning retail tenant mix in shopping malls. Procedia Social and Behavorial Sciences, 24(1), 317-324. https://doi.org/10.1016/j.sbspro.2011.09.124

Carter, S. (2011). Housing tenure choice and the dual income household. Journal of Housing Economics, 20(3), 159-170. https://doi.org/10.1016/j.jhe.2011.06.002

Case, B., Goetzmann, W., \& Rouwenhorst, K. (2000). Global real estate markets: cycles and fundamentals. National Bureau of Economic Research Working Paper 7566. Cambridge.

Cheng, P., Lin, Z., \& Liu, Y. (2008). A model of time-on-market and real estate price under sequential search with recall. Real Estate Economics, 36(4), 813-843. https://doi.org/10.1111/j.1540-6229.2008.00231.x

Chye, K., Chin, T., \& Peng, G. (2004). Credit scoring using data mining techniques. Singapore Management Review, 26(2), 25-47.

Cirman, A., Pahor, M., \& Verbic, M. (2015). Determinants of time on the market in a thin real estate market. Engineering Economics, 26(1), 4-11. https://doi.org/10.5755/j01.ee.26.1.3905

Eden, C. (1988). Cognitive mapping. European Journal of Operational Research, 36(1), 1-13.

https://doi.org/10.1016/0377-2217(88)90002-1

Eden, C. (2004). Analyzing cognitive maps to help structure issues or problems. European Journal of Operational Research, 159(3), 673-686. https://doi.org/10.1016/S0377-2217(03)00431-4

Eden, C., \& Ackermann, F. (2001). SODA - The principles. In J. Rosenhead \& J. Mingers (Eds.), Rational analysis for a problematic world revisited: problem structuring methods for 
complexity, uncertainty and conflict (pp. 21-41). (2nd ed.). Chichester: John Wiley \& Sons.

Eden, C., \& Ackermann, F. (2004). Cognitive mapping expert views for policy analysis in the public sector. European Journal of Operational Research, 152(3), 615-630. https://doi.org/10.1016/S0377-2217(03)00061-4

Ferreira, F. (2016). Are you pleased with your neighborhood? A fuzzy cognitive mapping-based approach for measuring residential neighborhood satisfaction in urban communities. International Journal of Strategic Property Management, 20(2), 130-141. https://doi.org/10.3846/1648715X.2015.1121169

Ferreira, F., Jalali, M., Bento, P., Marques, C., \& Ferreira, J. (2017a). Enhancing individual entrepreneurial orientation measurement using a metacognitive decision making-based framework. International Entrepreneurship and Management Journal, 13(2), 327-346. https://doi.org/10.1007/s11365-016-0388-5

Ferreira, F., Jalali, M., Meidute-Kavaliauskienè, I., \& Viana, B. (2015a). A metacognitive decision making based-approach to bank customer loyalty measurement and management. Technological and Economic Development of Economy, 21(2): 280300. https://doi.org/10.3846/20294913.2014.981764

Ferreira, F., Jalali, M., Zavadskas, E., \& Meidutė-Kavaliauskienė, I. (2017b). Assessing payment instrument alternatives using cognitive mapping and the Choquet integral. Transformations in Business \& Economics, 16(2|41), 170-187.

Ferreira, F., Marques, C., Bento, P., Ferreira, J., \& Jalali, M. (2015b). Operationalizing and measuring individual entrepreneurial orientation using cognitive mapping and MCDA techniques. Journal of Business Research, 68(12), 2691-2702. https://doi.org/10.1016/j.jbusres.2015.04.002

Ferreira, F., Santos, S., Rodrigues, P., \& Spahr, R. (2014). Evaluating retail banking service quality and convenience with MCDA techniques: A case study at the bank branch level. Journal of Business Economics and Management, 15(1), 1-21. https://doi.org/10.3846/16111699.2012.673504

Ferreira, F., Spahr, R., Sunderman, M., Banaitis, A., \& Ferreira, J. (2017c). A learning-oriented decision-making process for real estate brokerage service evaluation. Service Business, 11(3), 453-474. https://doi.org/10.1007/s11628-016-0315-4

Filipe, M., Ferreira, F., \& Santos, S. (2015). A multiple criteria information system for pedagogical evaluation and professional development of teachers. Journal of the Operational Research Society, 66(11), 1769-1782. https://doi.org/10.1057/jors.2014.129

Furick, M. (2006). Using neural networks to develop a new model to screen applicants for apartment rentals. PhD Thesis. Nova Southeastern University. Fort Lauderdale, FL, USA.

Gbadegesin, J., \& Oletubo, A. (2013). Analysis of tenant selection criteria in an emerging rental market. Global Journal of Management and Business Research Interdisciplinary, 13(7), 1-12.

Gonçalves, T., Ferreira, F., Jalali, M., \& Meidutè-Kavaliauskienė, I. (2016). An idiosyncratic decision support system for credit risk analysis of small and medium-sized enterprises. Technological and Economic Development of Economy, 22(4), 598-616.

Goodhart, C., \& Hofmann, B. (2007). House prices and the macroeconomy: implications for banking and price stability. Oxford: Oxford University Press.

Hjalmarsson, E., \& Hjalmarsson, R. (2009). Efficiency in housing markets: which home buyers know how to discount?. Journal of Banking \& Finance, 33(11), 2150-2163. https://doi.org/10.1016/j.jbankfin.2009.05.014

Jackson, J., Jones, C., \& Balsmeir, P. (1986). An empirical analysis of tenant selection under federal rent supplement programs: a first step. Real Estate Economics, 14(1), 72-90.

https://doi.org/10.1111/1540-6229.00370
Jalali, M., Ferreira, F., Ferreira, J., \& Meidute-Kavaliauskienė, I. (2016). Integrating metacognitive and psychometric decisionmaking approaches for bank customer loyalty measurement. International Journal of Information Technology \& Decision Making, 15(4), 815-837. https://doi.org/10.1142/S0219622015500236

Ju, L., Wenbin, X., \& Bei, Z. (2011). Construction of costumer classification model based on inconsistent decision table. International Journal of e-Education, e-Business, e-Management and e-Learning, 1(3), 269-273.

Keeney, R. (1992). Value-focused thinking: a path to creative decisionmaking. Harvard: Harvard University Press.

Keeney, R. (1996). Value-focused thinking: Identifying decision opportunities and creating alternatives. European Journal of Operational Research, 92(3), 537-549.

https://doi.org/10.1016/0377-2217(96)00004-5

Klein, J., \& Cooper, D. (1982). Cognitive maps of decision-makers in a complex game. Journal of the Operational Research Society, 33(1), 63-71. https://doi.org/10.1057/jors.1982.7

Kwahk, K., \& Kim, Y. (1999). Supporting business process redesign using cognitive maps. Decision Support Systems, 25(2), 155-178. https://doi.org/10.1016/S0167-9236(99)00003-2

Larsen, R., \& Sommervoll, D. (2009). The impact on rent from tenant and landlord characteristics and interaction. Regional Science and Urban Economics, 39(3), 316-322. https://doi.org/10.1016/j.regsciurbeco.2008.10.004

Lima, G. (2003). Interfaces entre a ciência da informação e a ciência cognitiva. Ciência da Informação, 32(1), 77-87. https://doi.org/10.1590/S0100-19652003000100008

Lin, Z., \& Liu, Y. (2008). Real estate returns and risk with heterogeneous investors. Real Estate Economics, 36(4), 753-776. https://doi.org/10.1111/j.1540-6229.2008.00229.x

Maier, G., \& Herath, S. (2009). Real estate market efficiency: a survey of literature. SRE Discussion Paper 2009-07, Wien.

Miceli, T., \& Sirmans, C. (1999). Tenant turnover, rental contracts and self-selection. Journal of Housing Economics, 8(4), 301-311. https://doi.org/10.1006/jhec.1999.0253

Montibeller, G., Ackermann, F., Belton, V., \& Ensslin, L. (2008). Reasoning maps for decision aid: an integrated approach for problem-structuring and multi-criteria evaluation. Journal of Operational Research Society, 59(5), 575-589. https://doi.org/10.1057/palgrave.jors.2602347

Olawande, O. (2011). Harnessing real estate investment through proper tenant selection in Nigeria. Property Management, 29(4), 383-397. https://doi.org/10.1108/02637471111154827

Poterba, J., Weil, D., \& Shiller, R. (1991). House price dynamics: the role of tax policy and demography. Brookings Papers on Economic Activity, 22(2), 143-203. https://doi.org/10.2307/2534591

Shaw, D., Ackermann, F., \& Eden, C. (2003). Approaches to sharing knowledge in group problem structuring. Journal of the Operational Research Society, 54(9), 936-948. https://doi.org/10.1057/palgrave.jors.2601581

Taskova, K., Stojanova, D., Bohanec, M., \& Dzerpski, S. (2007). A qualitative decision-support model for evaluating researchers. Informatica, 31(4), 479-486.

Yau, C., \& Davis, T. (1994). Using multi-criteria analysis for tenant selection. Decision Support Systems, 12(3), 233-244. https://doi.org/10.1016/0167-9236(94)90007-8

Zavadskas, E., \& Turskis, Z. (2011). Multiple criteria decision making (MCDM) methods in economics: an overview. Technological and Economic Development of Economy, 17(2), 397427. https://doi.org/10.3846/20294913.2011.593291

$\mathrm{Zu}$, Q., Wu, T., \& Wang, H. (2010). A multi-factor customer classification evaluation model. Computing and Informatics, 29(4), 509-520. 